\title{
"A Grande Família - O Filme" e "The Big Family - The Film": a tradução no ensino comunicativo de línguas
}

\author{
Marileide Dias Esqueda*, Rosana Carla de Oliveira ${ }^{\dagger} \mathrm{e}$ \\ Silvana Maria de J esus ${ }^{\ddagger}$
}

If real-life translation is emulated in the classroom, it will soon become clear to language students that expressions in the two languages do not necessarily correspond one-to-one, and that even when they do, the contexts for the two texts may differ so radically that the TL (Target Language) expression which is usually considered the closest "equivalent" of the SL (Source Language) expression is in fact unsuitable for TT (Target Text). In such situations, students will certainly be required to practice focused thinking in both languages. (MALMKJ AER 1998: 8)

Abstract: This work reports on the use of translation activities in foreign language classrooms - English Language Teaching - advanced level. Some dialogs of "The Big Family - The Film" were chosen in the pair of languages Portuguese-English, to be accomplished by the students as translation activity, whose purpose was to discuss their concepts on translation, about the translator and the translation for subtitling. Afterwards, the students compared their translation with the English version presented on the film DVD, which ended up modifying their assumptions about translation.

Keywords: Translation - Language teaching - Subtitling translation

\footnotetext{
Professora do Curso de Bacharelado em Tradução da Universidade Federal de Uberlândia/MG. Email: marileide esqueda@ileel.ufu.br.

${ }^{\dagger}$ Professora de Inglês e Tradutora - Bauru/ SP. Email: rosana_carla20@yahoo.com.br.

‡ Professora do Curso de Bacharelado em Tradução da Universidade Federal de Uberlândia/MG. Email: silanios@gmail.com.
} 
Resumo: Esta pesquisa tem como objetivo refletir sobre a inserção de atividades de tradução na sala de aula de língua estrangeira - inglês, nível avançado. Foram escolhidos alguns diálogos do filme "A Grande Família - O Filme" como atividade tradutória a ser realizada no eixo português-inglês junto aos alunos, a partir da qual se discutiu o conceito destes acerca da tradução, do tradutor e da tradução para produção de legendas. Os alunos contrastaram suas traduções com a versão em língua inglesa presente no DVD do filme, o que revelou modificar seus posicionamentos frente à tradução.

Palavras-chave: Tradução - Ensino de línguas - Tradução para produção de legendas. 
Esqueda, M. D.; Oliveira, R. C. e J esus, S.M. - "A Grande Família - 0

Filme" e "The Big Family - The Film": a tradução no ensino comunicativo de línguas

\section{Introdução e síntese da bibliografia fundamental}

0 método gramática e tradução, também chamado de método tradicional, constituiu-se historicamente como a primeira e mais antiga metodologia que serviu para ensinar as línguas clássicas como o grego e 0 latim. Com o tempo, porém, esta abordagem, que propunha a tradução como base de compreensão das línguas em estudo, passou a ser rejeitada no aprendizado de língua estrangeira (LE, daqui em diante), perdendo lugar para outras metodologias, principalmente por ser considerada artificial e mecânica, já que praticava a tradução de frases isoladas ou descontextualizadas.

Segundo Kirsten MALMKJ AER (1998):

Os argumentos contra a utilização da tradução no ensino de línguas foram levantados inicialmente no século XIX pelos membros do início do movimento da reforma, e reiterados com maior intensidade nas décadas de 60 e 70 pelas pessoas que acreditavam nos métodos direto, natural e/ ou comunicativo de ensino de línguas. 0 método por eles contestado era o "método gramática-tradução", que havia sido criado como uma forma de ensinar línguas modernas nas escolas secundárias na Prússia no fim do século XVIII (HowaTT, 1984: 131), baseado no então denominado método escolástico, tradicionalmente utilizado por pessoas que estudavam, independentemente, a forma escrita de uma língua, e também no ensino de latim e grego em escolas de gramática. O aluno estudava a gramática de uma língua e lia os textos, quase sempre religiosos ou literários, com a ajuda de um dicionário e da gramática adquirida. Este método claramente envolvia a escrita de significados coletados, especialmente nas fases iniciais - escrevendo, literalmente, a tradução de um texto. (MALMKJ AER 1998: 2; tradução nossa). ${ }^{1}$

\footnotetext{
${ }^{1}$ Arguments against using translation in language teaching were initially raised in the $19^{\text {th }}$ century by members of the early reform movement, and were largerly re-iterated in the 1960 s and 70 s by people who believed in the direct, natural, and/ or communicative methods of language teaching. The method they were objecting to was the so called 'grammar translation' method, which had been devised as a way of teaching modern languages in
} 
Esqueda, M. D. ; Oliveira, R. C. e J esus, S.M.- "A Grande Família - 0

Filme" e "The Big Family - The Film": a tradução no ensino

comunicativo de línguas

Segundo a autora, as novas abordagens que surgiram após o método gramática e tradução partiam do princípio que a língua é falada e não somente escrita, tornando-se, em essência, um conjunto de hábitos de fala. Ou seja, o ensino de línguas não deveria ser aquele que tomasse as formas da língua descritas nas gramáticas como o modelo suficiente para organizar as experiências de aprender outra língua, mas o que se baseasse em amostras autênticas.

0 abandono da tradução no ensino de línguas, neste sentido, teria ocorrido, muito provavelmente, pela crença de que tal atividade não leva em consideração fatos reais da língua falada e que supõe precisão e fixidez lexical.

SOUZA (1999 apud CUnHA 2007) expõe as principais crenças que levaram ao abandono da atividade de tradução na sala de aula de LE:

\section{Quadro 1 - Crenças sobre o uso da tradução em sala de aula}

- A tradução não é uma das habilidades básicas da aprendizagem de línguas, uma vez que saber uma língua significa OUVIR, FALAR, LER E ESCREVER.

- Traduzir é uma atividade artificial e difícil.

- A tradução induz o aluno a pensar na existência de correspondências ou equivalências exatas entre as palavras e estruturas de duas línguas.

- A tradução impede o aluno de pensar diretamente na língua estrangeira.

- Toda tradução é limitada. Não existe tradução perfeita.

- A tradução deve ser evitada na aula de língua estrangeira, porque vicia o aluno a traduzir tudo literalmente, palavra por palavra.

- Não existe tradução fiel ao original. Todo tradutor é um traidor. Cada tradutor interpreta e traduz o texto original de maneira diferente.

Fonte: SOUZA 1999 apud CUNHA 2007.

secondary schools in Prussia at the end of the eighteenth century (HOWATT 1984: 131) on the basis of the so-called scholastic method traditionally used by individuals studying the written form of a language independently, and also for teaching Latin and Greek in grammar schools: The scholar would study th egrammar of a language, and read texts, almost invariably religious or literary, with the help of a dictionary and the acquired grammar. This method would obviously normally involve writing down the meanings gleaned, particularly in the early stages effectively, writing down a translation of the text. 
A prioridade dada à metodologia oral fez com que o método gramática e tradução fosse predominantemente banido da sala de aula de LE, com a crença de que se resumia na criação de um processo simulado.

Este conceito reducionista sobre a tradução foi contestado por estudiosos envolvidos com a formação de tradutores que, na década de 70 , buscavam provar que a tradução envolve um processo complexo com uma variedade de componentes cognitivos (WILLS 1996). A atividade tradutória, neste sentido, envolve não uma escolha lexical fixa, baseada em uma lista de palavras isoladas, mas aquela relevante para a comunidade receptora e produzida em concórdia com as experiências do tradutor.

A partir de então, segundo MALMKJ AER (1998), a tradução passou a reconquistar respeitabilidade entre os profissionais do ensino de línguas. Por exemplo, a editora inglesa Oxford University Press publicou, entre as décadas de 80 e 90, uma série didática especialmente dirigida aos professores de línguas, intitulada Resources books for teachers (Duff 1989), na qual um dos volumes é dedicado ao ensino de tradução na sala de aula de LE. Recentemente, foi publicada a coletânea Translation in second language learning and teaching (WITTE et al. 2009), demonstrando o retorno da tradução à sala de aula.

Longe de ser uma atividade artificial, perfeita e viciada em um processo literal, a tradução mostra as diferenças entre as línguas, revela distintas noções culturais e discursivas dos falantes e evidencia como várias traduções podem ser dadas a um mesmo texto (escrito ou falado), dependendo do ideário do tradutor, isto é, de suas noções de mundo, cultura, tempo e lugar.

A favor da tradução na sala de LE, CHECCHIA (2002), RIDD (2003) e WeLKER (2003) discutem que a introdução de exercícios de tradução em sala de línguas estrangeiras pode ser, em determinadas situações, uma forma de abreviar rodeios ou explicações demoradas, em língua alvo, de determinados vocábulos desconhecidos aos alunos, principalmente para os iniciantes. No 
entanto, concordam que 0 antigo exercício de tradução de frases isoladas e descontextualizadas, empregado por meio do método gramática e tradução, caiu em desuso, especialmente em se tratando das atuais sociedades cuja base de relacionamento é a valorização de uma comunicação pragmaticamente clara e eficaz.

CHECCHIA (2002) argumenta que a tradução na sala de aula de LE exerce um papel integrador e emancipador, preenchendo lacunas vernaculares, aumentando a conscientização cultural, além de chamar atenção para as diferenças formais e linguísticas entre as duas línguas.

Neste sentido, RIDD (2003) também argumenta que podemos perceber uma nova interpretação da utilização da tradução em sala de aula. A tradução é um dos meios de se alcançar a comunicação e não deve ser tratada ou apresentada apenas como um produto final.

WeLKER (2004) recomenda o uso da tradução tanto da LE para a L1, quanto da $L 1$ para a $L E$, sendo que para o primeiro caso 0 autor sugere a utilização de textos autênticos que possam ser trazidos pelos alunos, mas com o cuidado de considerar o nível de dificuldade dos mesmos, a fim de não causar cansaço ou frustração. Já na tradução de $L 1$ para $L E$, atividade considerada mais complexa, os exercícios de tradução devem ser adaptados ao nível de conhecimento dos alunos. Ele sugere o uso de pequenos textos que já foram estudados na LE e traduzidos para a L1 e que possam ser retrotraduzidos.

AZENHA J ÚNIOR (2006), a favor do uso da tradução em sala de aula de LE, coloca em seu texto $O$ lugar da tradução na formação em letras: algumas reflexões, que o uso da tradução representa um ponto privilegiado em que teoria e prática, nas suas mais diversas configurações, interagem, estimulam a pesquisa autônoma e contribuem para a formação de uma reflexão crítica por parte do aluno.

Segundo esses autores, ao se introduzir a tradução de breves excertos na sala de aula de $L E$, pode-se, inclusive, fazer com que os alunos infiram que 
Esqueda, M. D.; Oliveira, R. C. e J esus, S.M. - "A Grande Família - 0

Filme" e "The Big Family - The Film": a tradução no ensino comunicativo de línguas

o processo de tradução palavra por palavra ou literal é um mecanismo errôneo possivelmente bastante utilizado por eles próprios.

CunHA (2007) argumenta que a tradução é, até certo ponto, inevitável para aprender as quatro habilidades básicas:

[...] isso faz com que a tradução seja uma atividade natural ao ambiente de aprendizado. Apesar de não existirem equivalências exatas, sempre haverá a significação aproximada. Essa aproximação deve ser buscada pelo aprendiz na procura de uma tradução mais adequada ao contexto. Em qualquer momento, podem haver inadequações de traduções, próprias do processo da comunicação e cabe ao professor explicitá-las aos alunos para que 0 aprendiz possa identificá-las. (CUNHA 2007: 24).

Buscando evidenciar que a tradução pode propiciar a percepção sobre a impossibilidade da literalidade entre as línguas, este trabalho obj etiva refletir sobre a inserção de atividades tradutórias na sala de aula de $L E$, a partir da utilização de excertos do filme "A Grande Família - O Filme", propondo a alunos de uma escola de idiomas de nível avançado de língua inglesa que os traduzam e os comparem, posteriormente, às legendas em língua inglesa presentes no DVD do filme. Importa ressaltar que, assim como em relação à tradução, a inserção de materiais fílmicos legendados na sala de aula de LE também sofre certo rechaço por parte de alguns profissionais de ensino de línguas.

CUNHA (2007) argumenta que:

0 uso de filmes legendados em sala de aula sofre uma rejeição por parte dos professores de LE que apenas os utilizam para atividades não ligadas diretamente ao ensino. Ou seja, atividades que não tem como objetivo o ensino das quatro habilidades. Alguns adeptos do método audiolingual chegaram até a criticar o uso das legendas, afirmando que elas desaceleram o processo de aprendizagem, pois tiram a atenção do aluno quanto aos aspectos orais e criam uma dependência do texto escrito. (CUNHA 2007: 22). 
Esqueda, M.D. ; Oliveira, R. C. e J esus, S. M. - "A Grande Família - 0

Filme" e "The Big Family - The Film": a tradução no ensino comunicativo de línguas

Ao tratar da tradução para produção de legendas, Araújo (2001) afirma que, por ser uma atividade muito difundida no Brasil, a tradução de filmes e programas de televisão por dublagem e legendagem é bastante criticada pelo público, pela imprensa e até pelos outros profissionais da tradução, público este que desconhece sobre a legendagem e todo o processo que a envolve.

Segundo a autora, a principal crítica à dublagem diz respeito à voz dos dubladores, mas, na legendagem, relaciona-se, mais especificamente, com a tradução de expressões estranhas para o falante nativo do português. De forma geral, sempre que se fala em legendagem se questiona a sua qualidade e se evidenciam os erros dos quais o espectador é vítima.

Alfaro (2005) explica que, na verdade, o processo de legendação é bastante complexo e que independe, muitas vezes, das decisões do tradutor:

\begin{abstract}
São vários os relatos de modificações significativas impostas ao texto traduzido por censuras linguísticas e ideológicas: linguagem de baixo calão é amenizada, componentes sexuais ou obscenos são minimizados ou excluídos e críticas a determinados grupos sociais ou culturais são substituídas. (AlFARO 2005: 95).
\end{abstract}

A pesquisadora discute que além das críticas de que a legendagem não revela exatamente 0 dito pelos personagens, surgem também julgamentos desfavoráveis com relação à qualidade da tradução, de que as legendas são menos "democráticas" por não permitirem o acesso aos espectadores da cultura de chegada não alfabetizados ou com dificuldade de leitura.

Em resposta a tais críticas, há também pesquisas que mostram que 0 emprego de legendas pode ajudar na alfabetização da população de estrangeiros residentes na cultura de chegada e no ensino de línguas estrangeiras. Em linhas gerais, as legendas são versões textuais nos diálogos presentes em filmes e programas de televisão, e um de seus fatores positivos radica em sua função didática.

CINTAS define a legendagem como "uma prática linguística que consiste em oferecer, geralmente na parte inferior da tela, um texto escrito que 
Esqueda, M. D.; Oliveira, R. C. e J esus, S.M.- "A Grande Família - 0

Filme" e "The Big Family - The Film": a tradução no ensino

comunicativo de línguas

pretende dar conta dos diálogos dos atores, assim como dos elementos discursivos que fazem parte da fotografia ou da trilha sonora (2003: 65; nossa tradução)". 2 Segundo ele, os filmes legendados são uma ferramenta muito importante no aprendizado de língua estrangeira:

Sem sombra de dúvidas, assistir e ouvir filmes legendados pode contribuir muito para o desenvolvimento das habilidades não apenas linguísticas, mas também na apreensão dos elementos e matizes culturais, e tudo de uma forma bastante lúdica. A trilha sonora é fonte de riqueza informativa referente tanto à entonação quanto à pronúncia das palavras, que é tão intensa em idiomas com fonética modificada, como no caso da língua inglesa. As legendas, por sua vez, redundam na dimensão semântica e aj udam a ampliar o vocabulário do aprendiz. (CINTAS 2003: 65; nossa tradução). ${ }^{3}$

Não apenas CinTAS (op. cit.) concorda com a função didática da legendagem, mas igualmente outros estudiosos têm se pronunciado a favor do uso das legendas em sala, defendendo a ideia de que a utilização de filmes legendados em sala de aula aumenta a motivação dos alunos no processo de aprendizagem. As legendas apresentam várias vantagens para o aprendizado de LE, podendo desenvolver diversas habilidades nos alunos. SouzA (1999 apud CUNHA, 2007) comenta sobre uma das vantagens da legenda em sala:

Como as legendas proporcionam a visualização das palavras que representam a fala no momento em que estão sendo ditas, os alunos associam sua forma oral à escrita. Esta exibição faz com que os alunos não precisem perder tempo procurando identificar as palavras em dois

\footnotetext{
${ }^{2}$ La subtitulación se puede definir como una práctica linguística que consiste en ofrecer, generalmente en la parte inferior de la pantalla, un texto escrito que pretende dar cuenta de los diálogos de los actores, así como de aquellos elementos discursivos que forman parte de la fotografía o de la pista sonora.

${ }^{3}$ Sin lugar a dudas el ver y oír películas subtituladas puede contribuir sobremanera al desarrollo de destrezas no solo linguísticas sino también de aprehensión de elementos y matices culturales, y todo ello de un modo bastante lúdico. La pista sonora es fuente de riqueza informativa en lo referente tanto a la entonación como a la pronunciación de palabras, tan exasperante en idiomas con fonética endiablada como el inglés. Los subtítulos, por su parte, redundan en la dimensión semántica y ayudan a ampliar el vocabulario del aprendiz.
} 
Esqueda, M. D.; Oliveira, R. C. e J esus, S.M.- "A Grande Família - 0

Filme" e "The Big Family - The Film": a tradução no ensino comunicativo de línguas

meios diferentes (papel e vídeo). Cada exposição gera um ganho cognitivo e a adição e a reformulação de estruturas cognitivas são propiciadas ainda mais pela combinação entre a linguagem visual, oral e escrita. (SOUSA 2004 apud CUNHA 2007: 20).

Além da associação entre a forma oral e escrita, o autor ainda acrescenta que a legenda tende a redobrar a atenção para o uso correto da ortografia do idioma ao desenvolver a capacidade de compreensão leitora. Neste sentido, o professor da sala de aula de LE pode desenvolver exercícios que explorem todas as habilidades linguístico-comunicativas ou, então, direcioná-los a uma habilidade específica.

\section{Objetivos}

Diante do exposto, o objetivo geral deste trabalho é refletir sobre a inserção da tradução na sala de aula de LE - inglês de nível avançado, a partir de uma experiência em uma escola de idiomas da cidade de Bauru-SP, com o intuito de discutir junto aos alunos que a tradução não se configura na transcrição de palavras isoladas de uma língua para a outra, mas em um processo de escolhas lexicais por parte de quem traduz. Almeja-se, ainda, com esta experiência, explicitar aos alunos que toda atividade de tradução envolve culturas diferentes.

Para tanto, foram traçados os seguintes obj etivos específicos:

1) conhecer o conceito de tradução dos alunos, bem como aquele relacionado à tradução para produção de legendas;

2) inserir exercícios tradutórios de alguns dos diálogos presentes no filme "A Grande Família - O Filme"; em seguida, solicitar que os alunos comparem suas traduções com as legendas em língua inglesa presentes 
no DVD do filme, com vistas a explorar as noções sobre significado e variedade de opções de tradução que subjazem à atividade;

3) analisar, após a inserção do exercício de tradução, o posicionamento dos alunos frente ao uso de tradução durante a aula de inglês.

Faz-se pertinente salientar que não se espera que os alunos produzam uma tradução profissional, como fariam tradutores-legendistas profissionais, que possuem competências específicas para tal. 0 intuito é que 0 aluno use sua habilidade de tradução natural para um exercício linguístico e cultural envolvendo tradução na aula de LE.

\section{Metodologia e Materiais}

Em primeiro lugar, esta pesquisa caracteriza-se como exploratóriobibliográfica, por buscar confluir os temas tradução, ensino de línguas e tradução para produção de legendas. Trata-se, em segunda instância, de uma pesquisa de caráter etnográfico, que por meio de dois questionários abertos (Q1 e Q2), um questionário fechado (QF) e de um formulário (F) com exercícios específicos de tradução para produção de legendas, objetivou, como exposto anteriormente, refletir sobre a inserção da tradução na sala de aula de LE.

O exercício de tradução envolveu alguns dos diálogos presentes no filme "A Grande Família - O Filme". A escolha deste material justifica-se 1) por se tratar de um filme baseado em uma das séries semanais de maior sucesso no Brasil, cujos personagens são conhecidos pela população brasileira, podendo despertar um maior interesse por parte dos alunos-participantes da pesquisa; 2) porque se encontra originalmente em português, possibilitando que os alunos comparem suas traduções com as legendas disponíveis em inglês no DVD, visto que outros estudos sobre a inserção de filmes na sala de aula de 
LE relatam utilizar legendas no eixo contrário, isto é, inglês-português (CUNHA 2007; ARAúj o 2003); 3) por apresentar uma linguagem coloquial e gíria que pode despertar a motivação e curiosidade dos alunos e, principalmente, porque tal linguagem evidencia a impossibilidade de se adotar uma tradução literal.

Embora muito conhecido, julga-se importante uma breve contextualização sobre o filme. Ao voltar do enterro de um colega de repartição, Lineu (interpretado por Marco Nanini) passa mal e vai ao médico, de onde sai com a certeza quase absoluta de que irá morrer. Deprimido, ele esconde sua situação da família e cancela a tradicional ida ao baile onde começou a namorar Nenê (interpretada por Marieta Severo). Sem entender as atitudes estranhas do marido, ela decide chamar sua atenção convidando para a festa um ex-namorado, Carlinhos (interpretado por Paulo Betti).

Toda a grande família Silva fica abalada com os fatos. Marilda (interpretada por Andréa Beltrão) se sente atraída por Carlinhos e resolve conquistá-lo. Augustinho (interpretado por Pedro Cardoso) e Tuco (interpretado por Lucio Mauro Filho) tentam tirar proveito da prosperidade do fã de Nenê. Na repartição, Mendonça (interpretado por Tonico Pereira) procura levantar o astral de Lineu, envolvendo-o com Marina (interpretada por Dira Paes), uma jovem funcionária.

A confusão piora quando Bebel (interpretada por Guta Stresser) anuncia que está grávida. Até mesmo Beiçola (interpretado por Marcos Oliveira) dá um basta às malandragens de Augustinho e Tuco. Pressionado por todos os lados, mas sem saber o que fazer, Lineu tenta evitar que a família sinta a sua morte. 0 resultado é que todos se sentem ameaçados, provocando situações que vão do drama à gargalhada. Seguem abaixo as informações técnicas do filme: 
Esqueda, M. D.; Oliveira, R. C. e J esus, S.M. - "A Grande Família - 0

Filme" e "The Big Family - The Film": a tradução no ensino comunicativo de línguas

Quadro 2 - Ficha técnica sobre "A Grande Família - 0 Filme"

Duração: 105 min

Gênero: Comédia

Direção: Maurício Farias

Co-Produção: Globo Filmes e Europa Filmes

Distribuidora: Europa Filmes

Estreia: 26 de J aneiro de 2007

Lançamento DVD: Abril de 2007

Idioma: Português

Legendas em: português, inglês, espanhol e francês

Bilheteria: Mais de dois milhões de telespectadores - 0 filme brasileiro mais visto em 2007

Elenco Principal: Andréa Beltrão- Marilda; Guta Stresser- Bebel; Lúcio Mauro Filho- Tuco; Marco Nanini- Lineu; Marieta Severo- Nenê; Pedro Cardoso- Augustinho.

\subsection{0 contexto e as etapas da investigação}

A pesquisa ocorreu na escola de idiomas FCE (First Class English) da cidade de Bauru-SP, que atualmente possui três unidades, todas dispondo de salas com computadores e salas de cinema, onde são realizadas atividades com música e filmes, facilitando assim os procedimentos desta investigação. A escola, fundada em 1995, adota o ensino comunicativo de línguas, sendo presumido o fato de que os alunos possuíssem certa noção de que as línguas não são amontoados de regras gramaticais, mas, se configuram como tomadas constantes de decisões por parte do falante, decisões estas que sofrem as 
influências dos contextos nos quais se encontram inseridos. Foram convidados 15 alunos de uma sala de aula de língua inglesa de nível avançado.

A primeira e a segunda etapas aconteceram na sala de vídeo de uma das unidades da escola e todas as discussões e comentários foram desenvolvidos em língua inglesa, daí o fato de que não se trata de inserir aleatoriamente a língua materna na sala de aula de LE, mas de estruturar pedagogicamente a atividade de tradução.

A primeira etapa consistiu em uma discussão acerca do tema tradução. Os alunos responderam ao Questionário 1 (Q1) contendo as seguintes perguntas:

a) O que é tradução para você? Defina tradução.

b) Você utiliza serviços de tradução? Você poderia citar algumas situações nas quais utiliza a tradução em sua vida diária?

c) 0 que é legendagem de filmes para você?

d) Você acha que a tradução deveria ser introduzida nas aulas de língua estrangeira? Qual sua opinião sobre isso?

Em seguida, os alunos assistiram ao filme "A Grande Família - O Filme" com áudio em português e sem as legendas em inglês. Na sequência, os alunos assistiram novamente apenas aos primeiros 15 minutos do filme e foi solicitado que analisassem, principalmente, o linguajar dos personagens.

$\mathrm{Na}$ terceira etapa, os alunos receberam um Formulário $(\mathbf{F})$ com alguns dos diálogos contendo linguajar coloquial e gírio dos mesmos primeiros quinze minutos do filme, para que pudessem fazer a tradução destes para a língua inglesa. Os alunos dirigiram-se à sala de multimídia, onde tiveram acesso à Internet e a vários dicionários impressos e online.

Os 15 primeiros minutos do filme continham as seguintes palavras ou expressões de caráter coloquial e gírio: "Deu uns amassos"; "Era só o que faltava"; "Climão, hein"; "Neguinho"; "Upa, neguinho, upa, neguinho"; “Dá 
Esqueda, M. D.; Oliveira, R. C. e J esus, S.M. - "A Grande Família - 0

Filme" e "The Big Family - The Film": a tradução no ensino comunicativo de línguas

pra ser ou tá difícil"; "Bonitão"; "Gamada"; "Deus não dá asa a cobra"; "Comidaiada". Os contextos nos quais tais palavras ou expressões foram utilizadas serão explicitados a seguir. Por questões de espaço, serão discutidos os resultados referentes às três primeiras expressões. As outras expressões, assim como suas traduções para a língua inglesa presentes no DVD do filme, constam no Apêndice 1 .

Após traduzirem os excertos, os participantes retornaram à sala de vídeo, onde foi feita uma discussão sobre as características dos personagens e seus respectivos linguajares, discussão esta realizada também em língua inglesa. Em seguida, verificou-se oralmente a tradução dos alunos para cada excerto.

Os alunos assistiram à cena novamente, porém, desta vez, com as legendas em inglês contidas no DVD, dando atenção especial aos excertos por eles traduzidos.

A etapa seguinte consistiu em uma discussão acerca da tradução (Questionário 2 - Q2). Aos alunos foram feitas as seguintes perguntas:

1- O seu conceito sobre tradução mudou após fazer este exercício? Explique.

2- 0 que é tradução?

3- Quais questões podem estar envolvidas em um processo de tradução?

4- A tradução também envolve questões culturais? Como a tradução para a produção de legendas retrata as diferenças culturais de uma língua para outra? Como o tradutor pode influenciar nesta troca cultural? 
Esqueda, M. D.; Oliveira, R. C. e J esus, S.M. - "A Grande Família - 0

Filme" e "The Big Family - The Film": a tradução no ensino comunicativo de línguas

Após a discussão, solicitou-se aos alunos que respondessem ao Questionário Final $(\mathbf{Q F})^{4}$ sobre a atividade tradutória em si. 0 questionário continha os seguintes questionamentos:

\section{Parte 1}

1. Você achou que a atividade foi:

( ) cansativa

( ) agradável

( ) bastante proveitosa em termos de aprendizagem

( ) pouco proveitosa em termos de aprendizagem

( )

2. O tempo gasto com a tradução foi:

( ) suficiente

( ) insuficiente

( ) excessivo

( )

3. O exercício de tradução de fragmentos do filme A Grande Família - O Filme foi:

( ) difícil

( ) parcialmente difícil

( ) muito difícil

( ) fácil

( ) razoavelmente fácil

( ) muito fácil

( )

\section{Parte 2}

4. Na sua opinião, de que maneira a tradução pode auxiliar na aprendizagem de línguas estrangeiras?

5. Você acha que a tradução tem a mesma utilidade que as outras atividades?

( ) $\operatorname{sim}$

( ) não

6. Que tipo(s) de exercício(s) de tradução você gostaria de ter e com que frequência? ( ) tradução escrita de texto inglês-português

\footnotetext{
${ }^{4}$ Campregher (2006) desenvolveu questionário similar para avaliar o impacto da tradução na sala de aula de LE - inglês, nível básico - aplicado junto a alunos e professores.
} 
Esqueda, M. D.; Oliveira, R. C. e J esus, S.M. - "A Grande Família - 0

Filme" e "The Big Family - The Film": a tradução no ensino comunicativo de línguas

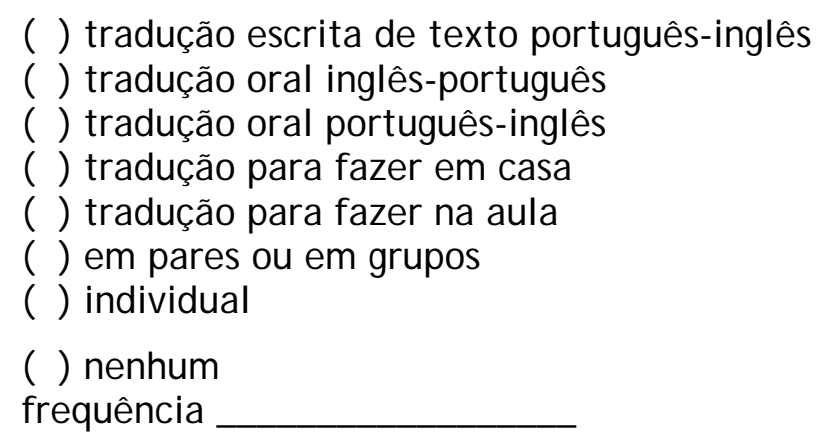

7. Qual(is) área(s) da tradução você gostaria de conhecer e exercitar, eventualmente, em sala de aula?

( ) tradução jornalística

( ) tradução literária

( ) tradução científica

( ) tradução técnica

( ) tradução jurídica

( ) tradução comercial

( ) tradução para produção de legendas e dublagens de filmes, home-videos ou documentários etc.

( ) tradução de músicas

( ) tradução de peças de teatro

( ) tradução para localização

( ) interpretação simultânea ou consecutiva Observações Finais:

\section{Análise e discussão dos resultados}

Dos 15 alunos convidados, apenas três alunos participaram da pesquisa, sendo que o restante relatou falta de disponibilidade.

No que se refere ao Q1, os três respondentes afirmaram que traduzir é passar de uma língua para outra; que utilizam serviços de tradução nas seguintes situações: para ler livros, assistir filmes e navegar na Internet; que 
legendagem é algo mecânico e que a tradução poderia ser introduzida na sala de aula de LE para melhorar o aprendizado do inglês.

Dentre os dados obtidos, percebe-se que, predominantemente, os alunos possuem a crença de que traduzir, e também legendar, é um ato de transporte linguístico automático; de que a tradução ocorre apenas na esfera editorial, fílmica e da Internet, o que supõe falta de conhecimento com relação a outros setores do mercado que utilizam a tradução; e de que a tradução na sala de aula de LE pode auxiliar na aprendizagem, sem relatar exatamente de que maneira.

Expõem-se, a seguir, em forma de quadros, as expressões traduzidas pelos alunos para a língua inglesa, presentes no formulário do exercício de tradução $(F)$. Como dito anteriormente, apenas as três primeiras serão expostas e discutidas. Os quadros estão divididos em quatro colunas, sendo que a primeira contém o sentido literal da palavra ou expressão, buscado em dicionários da língua portuguesa pelos alunos; a segunda, o sentido da palavra ou expressão no diálogo ou contexto, a terceira coluna refere-se à tradução feita pelos alunos, e a última coluna contém a tradução para a língua inglesa presente no DVD do filme.

Anterior ao quadro, expõe-se as cenas (figuras 1, 2 e 3) e o contexto referente a estas, a partir do qual as palavras ou expressões foram proferidas.

Com relação à Expressão 1, Marilda (interpretada por Andréa Beltrão), ao querer saber até qual "etapa" chegou a relação de Nenê (interpretada por Marieta Severo) e Carlinos (interpretado por Paulo Betti), em quem estava interessada, pronuncia a expressão: “Deu uns amassos?" 
Esqueda, M. D.; Oliveira, R. C. e J esus, S.M. - "A Grande Família - 0

Filme" e "The Big Family - The Film": a tradução no ensino comunicativo de línguas

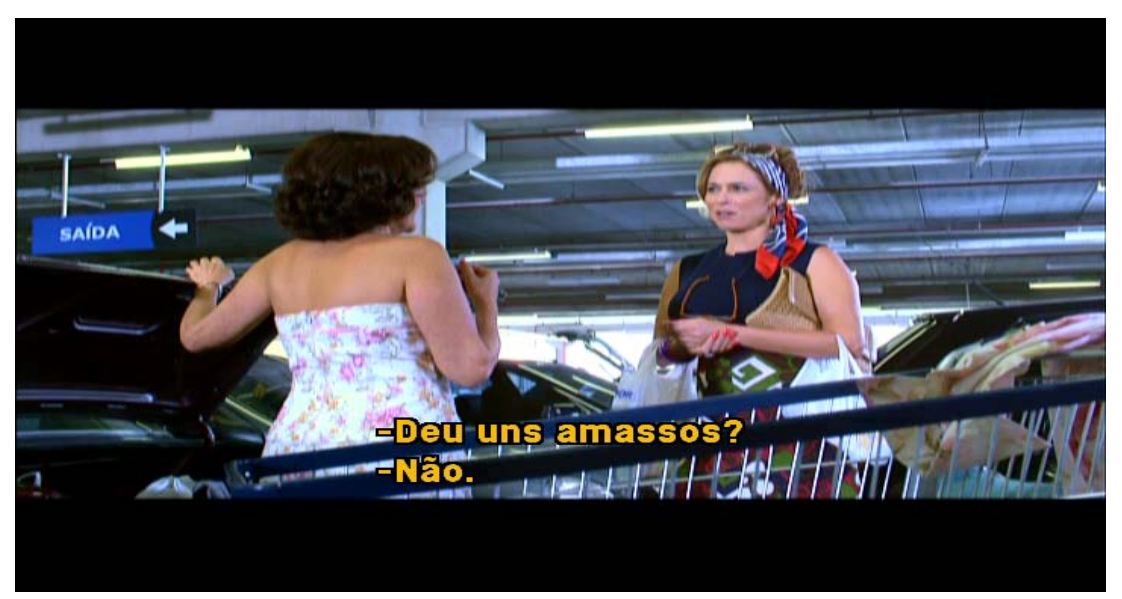

Figura 1 - Legenda (Expressão 1). In: A GRANDE FAmíliA - 0 FILME. Direção: Maurício Farias. [S.L.]:

Globo Filmes e Europa Filmes, 2007.

Quadro 3 - Decisões tomadas pelos alunos para a tradução da expressão 1

\begin{tabular}{|c|c|c|c|}
\hline $\begin{array}{c}\text { Sentido literal da } \\
\text { palavra }\end{array}$ & Sentido na frase & Tradução dos alunos & $\begin{array}{c}\text { Tradução presente no } \\
\text { DVD do filme }\end{array}$ \\
\hline $\begin{array}{c}\text { Amassos - } \\
\text { substantivo } \\
\text { masculino } \\
\text { 1- Ato ou efeito de } \\
\text { amassar; } \\
\text { amassadura, } \\
\text { amassamento, } \\
\text { amassado. } \\
\text { 2-Regionalismo: } \\
\text { Brasil. Uso: informal. } \\
\text { Abraço ou apalpação } \\
\text { de caráter amoroso } \\
\text { ou libidinoso; } \\
\text { esfregação. }\end{array}$ & $\begin{array}{l}\text { Abraço ou } \\
\text { apalpação de } \\
\text { caráter amoroso } \\
\text { ou libidinoso; } \\
\text { esfregação. }\end{array}$ & $\begin{array}{l}\text { Aluno } \mathbf{1} \text { - Hang out for } \\
\text { some kisses? } \\
\text { Aluno } \mathbf{2} \text { - Have you } \\
\text { dangle? } \\
\text { Aluno } \mathbf{3} \text { - Have you gone } \\
\text { out with him? }\end{array}$ & Necked a little? \\
\hline
\end{tabular}

No caso da Expressão 2, Lineu (interpretado por Marco Nanini), além de ter que suportar a presença do ex-namorado de Nenê no jantar, recebe a notícia de que Bebel (interpretada por Guta Stresser) está esperando um filho de Augustinho (interpretado por Pedro Cardoso), que é criticado por Lineu por não ter emprego e salário fixos e por estar sempre envolvido em 
Esqueda, M. D.; Oliveira, R. C. e J esus, S.M. - "A Grande Família - 0

Filme" e "The Big Family - The Film": a tradução no ensino comunicativo de línguas

malandragens. Lineu indigna-se com 0 fato de ser avô em breve, principalmente por achar que tem pouco tempo de vida, pronunciando então a expressão "Era só o que faltava!":

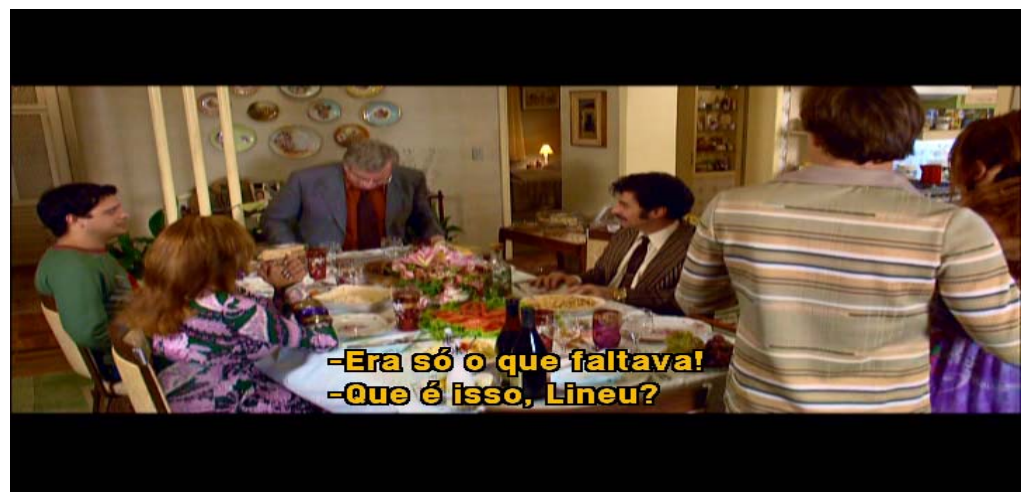

Figura 2 - Legenda (Expressão 2). In: A GRAnde FamíliA - 0 FILME. Direção: Maurício Farias. [S. L. ]: Globo Filmes e Europa Filmes, 2007.

\section{Quadro 4 - Decisões tomadas pelos alunos para a tradução da expressão 2}

\begin{tabular}{|c|c|c|c|}
\hline $\begin{array}{l}\text { Sentido literal da } \\
\text { palavra }\end{array}$ & Sentido na frase & Tradução dos alunos & $\begin{array}{c}\text { Tradução presente no } \\
\text { DVD do filme }\end{array}$ \\
\hline $\begin{array}{l}\text { Faltar algo - verbo } \\
\text { transitivo indireto } \\
\text { e intransitivo } \\
\text { 1- Sentir(-se) a } \\
\text { ausência ou } \\
\text { necessidade de algo } \\
\text { ou alguém; carecer; } \\
\text { escassear; não existir } \\
\text { ou deixar de haver. } \\
\text { 2- Desaparecer, } \\
\text { morrer. } \\
\text { 3- Ser indispensável } \\
\text { para que se } \\
\text { complete algo. } \\
\text { 4- Deixar de fazer ou } \\
\text { de cumprir; falhar. }\end{array}$ & $\begin{array}{l}\text { Não acredito } \\
\text { nisso. }\end{array}$ & $\begin{array}{l}\text { Aluno } \mathbf{1} \text { - You got be } \\
\text { kidding me! } \\
\text { Aluno } \mathbf{2} \text { - That's all I } \\
\text { needed! } \\
\text { Aluno } \mathbf{3} \text { - This is too } \\
\text { much for me! }\end{array}$ & $\begin{array}{l}\text { That just takes the } \\
\text { cake! }\end{array}$ \\
\hline
\end{tabular}


Esqueda, M. D. ; Oliveira, R. C. e J esus, S.M.- "A Grande Família - 0

Filme" e "The Big Family - The Film": a tradução no ensino comunicativo de línguas

Na sequência da cena anterior, Tuco (Lúcio Mauro Filho) profere a frase "Climão, hein?" (Expressão 3), depois que Lineu se levanta da mesa do jantar, indignado com a presença de Carlinhos e com a gravidez de Bebel.

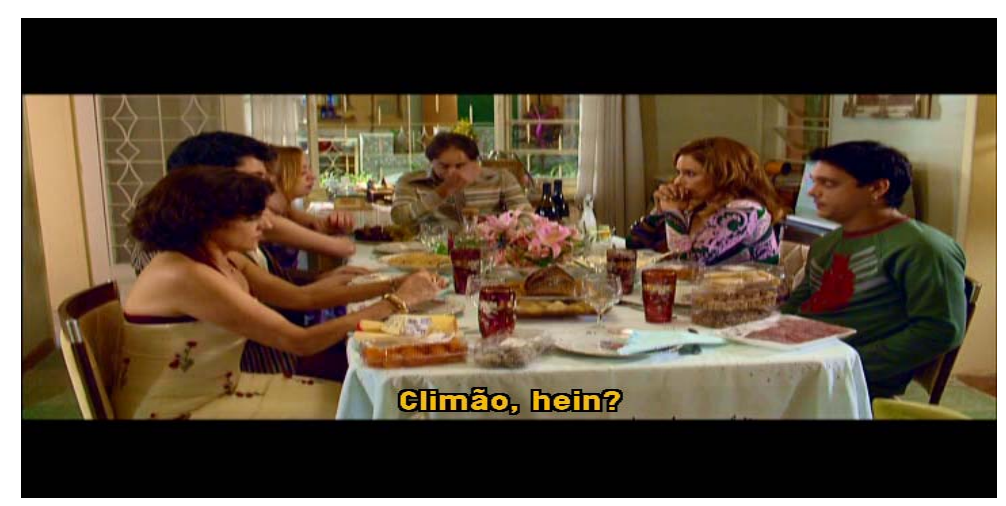

Figura 3 - Legenda (Expressão 3). In: A GRANDE FAmílIA - O FILME. Direção: Maurício Farias. [S. L. ]: Globo Filmes e Europa Filmes, 2007.

Quadro 5 - Decisões tomadas pelos alunos para a tradução da expressão 3

\begin{tabular}{c|c|l|c}
\hline Sentido literal da palavra & Sentido na frase & Tradução dos alunos & $\begin{array}{c}\text { Tradução } \\
\text { presente no DVD } \\
\text { do filme }\end{array}$ \\
\hline $\begin{array}{c}\text { Clima: substantivo } \\
\text { masculino }\end{array}$ & $\begin{array}{c}\text { Ambiente ou } \\
\text { situação } \\
\text { desagradável }\end{array}$ & $\begin{array}{l}\text { Aluno 1 - heavy, don't } \\
\text { it? } \\
\text { Aluno 2 - bad } \\
\text { atmosféricas que } \\
\text { atmosphere, isn't it? } \\
\text { caracterizam uma região, } \\
\text { pela influência que exercem } \\
\text { sobre a vida na Terra. } \\
\text { 2- Ambiente favorável ou } \\
\text { não para a realização de } \\
\text { determinada coisa; meio; } \\
\text { atmosfera moral } \\
\text { situation, hein? }\end{array}$ & $\begin{array}{c}\text { Such a nice } \\
\text { atmosphere, } \\
\text { huh! }\end{array}$ \\
$\begin{array}{c}\text { 3- Ambiente favorável para } \\
\text { um encontro amoroso } \\
\text { âo - sufixo aumentativo }\end{array}$ & & \\
\hline
\end{tabular}

As traduções realizadas pelos alunos ilustram a prevalência de que eles não buscaram uma tradução literal para as expressões "Deu uns amassos", "Era só o que faltava" e "Climão, hein?", e os resultados obtivos sugerem que 
os alunos se empenharam em buscar diferentes recursos linguísticos para a realização do exercício. Como a atividade foi realizada no laboratório de multimída da escola, um dos alunos, além de promover buscas em vários dicionários impressos e online, acessou um site de bate-papo com estrangeiros a fim de perguntar-Ihes sobre as expressões. Apesar deste empenho, ${ }^{5}$ os alunos não chegaram a propor a mesma solução às expressões apresentadas na legenda oficial do DVD, o que os fez concluir que há várias possibilidades de tradução de uma mesma palavra ou expressão.

GOROVITZ (2007), neste prisma, explica que a inserção de atividades fílmicas em sala de aula de LE, tendo a tradução como recurso pedagógico, enriquece o repertório linguístico por meio do qual o aluno tem contato com perspectivas socioculturais distintas.

SCHWEERS (1999 apud CUNHA 2007) também afirma que o uso da tradução e da língua materna em sala permite ao aluno a manutenção de sua identidade cultural.

0 exercício tradutório pode, ainda, auxiliar na ortografia das palavras. A tradução para produção de legendas tende a redobrar a atenção para o uso correto da ortografia dos idiomas, ao desenvolver a capacidade de compreensão leitora e expressão escrita no momento da busca de equivalentes, além da otimização do uso de dicionários e poder de escolha e decisão por parte dos alunos.

Por fim, de uma forma dinâmica, ainda é possível trabalhar a expressão oral com os alunos durante a atividade, propondo uma discussão sobre o filme assistido e caracterizando oralmente os personagens, como realizado nesta pesquisa, entre outras propostas que irão depender da criatividade do professor. Neste estudo, os alunos tiveram a chance de praticar sua expressão oral, visto que todas as interações foram feitas em língua inglesa. Ressalta-se que tais interações foram gravadas em vídeo como forma de registro das

\footnotetext{
${ }^{5}$ Os erros gramaticais cometidos nas traduções para a língua inglesa foram corrigidos durante o exercício.
} 
Esqueda, M. D.; Oliveira, R. C. e J esus, S.M. - "A Grande Família - 0

Filme" e "The Big Family - The Film": a tradução no ensino comunicativo de línguas

informações e isto contribuiu, também, para a desinibição dos alunos, bem como para a própria autoavaliação. Durante a coleta dos dados, os alunos não tiveram a chance de assistir às gravações; entretanto, esta seria uma maneira de avaliarem o seu desempenho, o que confirma o exposto por TUDOR (2001), de que a tradução no ensino de LE pode ser usada de várias maneiras como uma atividade comunicativa.

Os quadros subsequentes mostram os dados referentes ao Q2, que almejou verificar as respostas dos alunos participantes da pesquisa frente à tradução após a inserção do exercício:

Quadro 6 - Resumo das respostas dos alunos na discussão feita após a inserção do exercício de tradução (Q2)

1- 0 seu conceito sobre tradução mudou após o exercício? Explique.

- Sim. É necessário pesquisar bastante e fazer escolhas corretas.

\section{2- 0 que é tradução?}

- Não é equivalência de palavras exatas.

3- Quais questões podem estar envolvidas em um processo de tradução?

- A mudança de palavras para adaptar melhor o sentido na frase, a personalidade do personagem (tipo de linguagem), cultura, contexto.

4- A tradução trata de questões culturais? Como a tradução/legendagem pode retratar a cultura de uma língua para outra? Como o tradutor pode influenciar nesta troca cultural?

- Sim, porque um filme pode mostrar a cultura de um país e este é visto por pessoas de outros países. O tradutor influencia porque é ele quem faz o texto que será lido pelo estrangeiro, ele é o responsável.

Comparando-se Q1 e Q2, nota-se que os alunos se mostraram mais confiantes em suas respostas sobre os conceitos e as denifições que envolvem a tradução.

No QF, os participantes responderam que a atividade foi proveitosa em termos de aprendizagem e todos concordaram que a tradução tem a mesma utilidade que outras atividades desenvolvidas na sala de aula de LE. Quanto ao grau de dificuldade do exercício, os alunos 1 e 2 responderam que a atividade 
Esqueda, M. D.; Oliveira, R. C. e J esus, S.M. - "A Grande Família - 0

Filme" e "The Big Family - The Film": a tradução no ensino

comunicativo de línguas

foi razoavelmente fácil e para 0 aluno 3 a atividade foi considerada parcialmente difícil. Com relação ao tempo gasto de três horas com 0 exercício de tradução, todos disseram ter sido suficiente, e quando questionados sobre a frequência com que gostariam de ter este tipo de atividade, 0 aluno 1 respondeu semanalmente e os alunos 2 e 3 quinzenalmente.

As respostas às questões 4, 6 e 7 do QF encontram-se explicitadas no quadro abaixo.

Quadro 7 - Respostas dos alunos às questões 4, 6 e 7 do questionário final (QF)

\begin{tabular}{|c|c|c|}
\hline $\begin{array}{l}\text { Questão 4: Na sua opinião, } \\
\text { de que maneira a tradução } \\
\text { pode auxiliar na } \\
\text { aprendizagem de línguas } \\
\text { estrangeiras? }\end{array}$ & $\begin{array}{l}\text { Questão 6: Que tipo(s) de } \\
\text { exercício(s) de tradução } \\
\text { você gostaria de ter? }\end{array}$ & $\begin{array}{l}\text { Questão 7: Qual(is) área(s) da } \\
\text { tradução você } \\
\text { conhecer gostaria de } \\
\text { eventualmente, em sala de } \\
\text { aula? }\end{array}$ \\
\hline $\begin{array}{l}\text { Aluno 1: Ajuda a entender } \\
\text { melhor a cultura, a língua, } \\
\text { os ditos populares etc. }\end{array}$ & $\begin{array}{l}\text { Aluno 1: Tradução oral } \\
\text { inglês-português; tradução } \\
\text { oral português-inglês em } \\
\text { pares ou em grupos. }\end{array}$ & $\begin{array}{l}\text { Aluno 1: Tradução literária; } \\
\text { tradução para produção de } \\
\text { legendas e dublagens de filmes, } \\
\text { home-videos ou documentários } \\
\text { etc.; tradução de músicas; } \\
\text { tradução de peças de teatro; } \\
\text { interpretação simultânea ou } \\
\text { consecutiva. }\end{array}$ \\
\hline $\begin{array}{l}\text { Aluno 2: A tradução nos } \\
\text { transmite conhecimento } \\
\text { sobre expressões e gírias } \\
\text { estrangeiras, enriquecendo } \\
\text { nosso vocabulário. }\end{array}$ & $\begin{array}{l}\text { Aluno 2: Tradução escrita } \\
\text { de texto português-inglês; } \\
\text { tradução oral inglês- } \\
\text { português em pares ou em } \\
\text { grupos. }\end{array}$ & $\begin{array}{l}\text { Aluno 2: Tradução jornalística; } \\
\text { Tradução para produção de } \\
\text { legendas e dublagens de filmes, } \\
\text { home-videos ou documentários } \\
\text { etc.; tradução de músicas. }\end{array}$ \\
\hline $\begin{array}{l}\text { Aluno 3: Principalmente } \\
\text { nas expressões e gírias que } \\
\text { são comuns no país } \\
\text { estrangeiro. }\end{array}$ & $\begin{array}{l}\text { Aluno 3: Tradução escrita } \\
\text { de texto português-inglês; } \\
\text { tradução escrita de texto } \\
\text { inglês-português; tradução } \\
\text { para fazer na aula ou em } \\
\text { grupos. }\end{array}$ & $\begin{array}{l}\text { Aluno 3: Tradução para } \\
\text { produção de legendas e } \\
\text { dublagens de filmes, home- } \\
\text { videos ou documentários, etc; } \\
\text { tradução de músicas. }\end{array}$ \\
\hline
\end{tabular}




\section{Conclusão}

Ao longo desta pesquisa buscou-se, primeiramente, conhecer o conceito de tradução dos alunos de inglês com nível avançado de uma escola de idiomas, para posterior aplicação de um exercício de tradução para produção de legendas. A atividade foi inserida com o objetivo de averiguar 0 posicionamento dos alunos frente ao uso de tradução durante a aula de inglês, bem como despertar-Ihes uma visão mais ampla da tradução e do processo tradutório, destacando os benefícios de um exercício de tradução para o aprimoramento das habilidades linguísticas.

Os autores citados nesta pesquisa defendem o uso da tradução na sala de aula de $L E$, argumentando que ela exerce um papel integrador e emancipador, preenchendo lacunas vernaculares, aumentando a conscientização cultural, além de chamar atenção para as diferenças formais e linguísticas entre as duas línguas.

Este estudo discutiu e buscou mostrar com a pesquisa empírica que a eficácia da tradução em sala é alcançada a partir do momento em que a mesma não é mais considerada uma atividade mecânica, tanto por parte dos professores quanto por parte dos alunos.

\section{Referências bibliográficas}

Alfaro, C. de C. A tradução para legendas: dos polissistemas à singularidade do tradutor. 160f. Dissertação (Mestrado em Estudos da Linguagem) Pontifícia Universidade Católica, 2005.

ARAújo, V. L. S. Por que não são naturais algumas traduções de clichês produzidas para o meio audiovisual. Tradução e Comunicação, n.10. São Paulo, 2001: 139-152.

- Glossário Bilíngue de clichês produzidas para 0 meio audiovisual. The Especialist. v. 23, n. 2. São Paulo, 2003: 139-154. 
AZENHA J ÚNIOR, J. O lugar da tradução na formação em letras: algumas reflexões. In: Cadernos de Tradução, v. 17, 2006: 158-187.

CHECCIA, R. L. T. O retorno do que nunca foi: o papel da tradução no ensino do inglês como língua estrangeira. 163p. Dissertação de Mestrado Instituto de Letras, Departamento de Línguas Estrangeiras, Universidade de Brasília, Brasília, 2002.

CINTAS, J. D. Teoria e práctica de la subtitulación. Barcelona: Ariel, 2003.

COMPREGHER, S. Ap. Tradução e ensino comunicativo de inglês como língua estrangeira: uma combinação possível? Monografia apresentada às Faculdades Integradas de Ourinhos-SP, Fundação Educacional "Miguel Mofarrey" para obtenção do título de Especialista em Ensino de Língua Inglesa, sob a orientação da Profạ Drạ Marileide Dias Esqueda. 72 p., 2006.

CUNHA, T. M. O uso de filmes legendados e do ensino comunicativo de línguas no desenvolvimento da proficiência oral em nível básico de língua estrangeira. 158f. Dissertação de Mestrado em Linguística Aplicada Universidade Estadual do Ceará, Fortaleza, 2007. Disponível em: বhttp:// www. uece. br/ cmlanovo/ disserta/ tiagomartinsdacunha. pdf >. (12/ 12/ 2010).

Duff, A. Translation. Oxford: Oxford University Press, 1989.

GoRovitZ, S. Os labirintos da tradução: a legendagem cinematográfica e a construção do imaginário. Brasília: Editora da UNB, 2007.

MALMKJ AER, K. (ed.). Translation \& language teaching: Language Teaching \& Translation. United Kingdom: St. J erome Publishing, 1998.

RIDD, M. D. Um casamento estranhamente ideal: a compatibilidade de gênios entre comunicativismo e tradução. Horizontes de Lingüística Aplicada, Brasília, v. 2, n. 1, 2003: 93-104.

TUDOR, I. The Dynamics of the Language Classroom. Cambridge: Cambridge University Press, 2001.

WeLKER, H. A. Traduzir frases isoladas na aula de língua estrangeira: por que não? Horizontes de Lingüística Aplicada, Brasília, v. 2, n. 2, 2003: 149-161.

WILLS, W. Translation as Intelligent Behaviour. In. H. Somers (ed.). Terminology, LSP and Translation: Studies in Language Engineering in Honour of J uan C. Sager. Amsterdam: J ohn Benjamins, 1996.

WitTE, Arnd et al. (ed.). Translation in second language learning and teaching. Oxford/ Bern: Peter Lang, 2009. 
Esqueda, M.D.; Oliveira, R. C. e J esus, S.M.- "A Grande Família - 0

Filme" e "The Big Family - The Film": a tradução no ensino comunicativo de línguas

\section{Filmografia}

A Grande Família - O filme. Direção: Maurício Farias. Roteiristas: Cláudio Paiva, Guel Arraes. Idioma: português. Legendas: português, inglês, espanhol e francês. Tradução para o inglês: Michele Aguiar Vartuli. Intérpretes: Andréa Beltrão; Guta Stresse; Lúcio Mauro Filho; Marco Nanini; Marieta Severo; Pedro Cardoso; Paulo Betti e outros. [S.L.]: Globo Filmes e Europa Filmes, 2007. 1 filme (105 min).

\section{Apêndice - Texto original e as legendas em inglês presentes no DVD.}

\begin{tabular}{|c|c|}
\hline$\underline{01: 08: 43.09}$ & $\underline{01: 08: 43.09}$ \\
\hline NO SUPERMERCADO & AT THE SUPERMARKET \\
\hline $\begin{array}{llr}\text { (CARLINHOS) } & \text {-Atenção, } & \text { repositores, } \\
\text { precisamos } & \text { resolver esse } & \text { problema }\end{array}$ & $\begin{array}{l}\text { (CARLINHOS) -Attention on the shelves, we } \\
\text { need to fix that immediately. }\end{array}$ \\
\hline $\begin{array}{l}\text { Levem as caixas pro setor de congelados, } \\
\text { por favor. }\end{array}$ & $\begin{array}{l}\text { Take those crates to the Frozen Foods } \\
\text { department, please. }\end{array}$ \\
\hline (NENÊ) -Carlinhos? & (NENÊ) -Carlinhos? \\
\hline (CARLINHOS) -Nenê? & (CARLINHOS) -Nenê? \\
\hline$[\ldots]$ & {$[\ldots]$} \\
\hline (MARILDA) -Aquele é seu ex-namorado? & (MARILDA) -So that's your ex-boyfriend? \\
\hline (NENÊ) -Ele não é meu ex-namorado. & (NENÊ) -He's not my ex-boyfriend. \\
\hline Na verdade, a gente nem namorou. & Actually, we didn't even date. \\
\hline A gente... a gente... só... & We just... we... just... \\
\hline (MARILDA) - Deu uns amassos? & (MARILDA) - Necked a little? \\
\hline (NENÊ) -Não. & (NENÊ) - No. \\
\hline
\end{tabular}


Esqueda, M. D.; Oliveira, R. C. e J esus, S.M.- "A Grande Família - 0

Filme" e "The Big Family - The Film": a tradução no ensino comunicativo de línguas

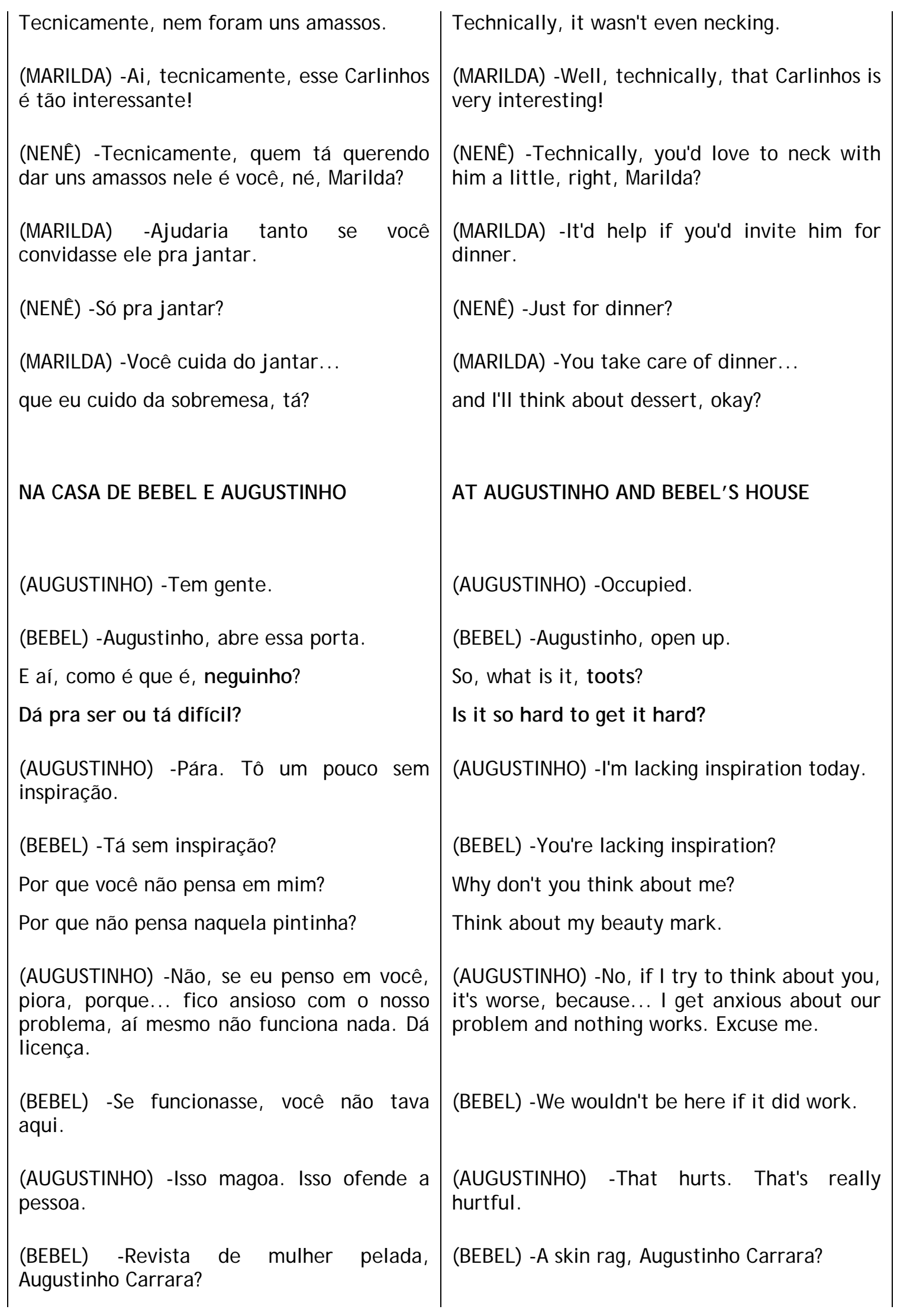


Esqueda, M. D.; Oliveira, R. C. e J esus, S.M.- "A Grande Família - 0

Filme" e "The Big Family - The Film": a tradução no ensino

comunicativo de línguas

(AUGUSTINHO) -Maria Isabel, é porque, numa situação assim, a pessoa se sente sozinha... ...e isso é um apoio, um estímulo.

(BEBEL) -Tá precisando de estímulo, é, amor? Pode deixar que eu te estimulo.

Upa, neguinho. Upa, neguinho.

\section{NA CASA DE LINEU E NENÊ - O J ANTAR}

(MARILDA) -Boa noite, Lineu.

(LINEU) -Boa noite.

(NENÊ) -Oi, Lineuzinho. E aí, como é que foi o enterro do Pacheco?

(LINEU) -Não foi muito animado, não.

Pra que essa mesa toda enfeitada?

(TUCO) -Tem visita hoje pro jantar. Essas duas tão arrumando a mesa há horas.

(MARILDA) -Lineu, sabe quem a gente encontrou no supermercado?

O ex-namorado da Nenê!

(NENÊ) -Ele não é meu ex-namorado, Marilda.

(MARILDA) - Mas podia ser.

Você não namorou o bonitão

porque já tava gamada no Lineu.

(LINEU) -E então vocês resolveram chamar o bonitão pra jantar.

(TUCO) -Deve ser o bonitão.

(CARLINHOS) -Boa noite. Eu trouxe umas lembrancinhas...

pra um jantar cheio de grandes lembranças.
(AUGUSTINHO) -It's just that, in a situation like this, a guy feels alone....... and this is just for stimulation.

(BEBEL) -So you need stimulation, love? I'll stimulate you, then. Come on,

rise and shine. Rise and shine.

AT NENÊ AND LINEU'S HOUSE - THE DINNER

(MARILDA) -Good evening, Lineu.

(LINEU) -Good evening.

(NENÊ) - Hi, Lineuzinho. So, what was

Pacheco's funeral like?

(LINEU) -Not very cheerful.

Why is the table all dressed up?

(TUCO) - We got a guest for dinner. They've been setting up the table for hours.

(MARILDA) -Lineu, guess who we bumped into at the supermarket!

Nenê's ex-boyfriend!

(NENÊ) -He's not my ex-boyfriend, Marilda.

(MARILDA) -But he could be.

You just didn't date Mr. Handsome

cuz you were in love with Lineu.

(LINEU) -So you decided to invite $\mathbf{M r}$. Handsome for dinner.

(TUCO) - That must be Mr. Handsome.

(CARLINHOS) -Good evening. I've brought a little something...

for a dinner full of big memories. 
Esqueda, M. D.; Oliveira, R. C. e J esus, S.M.- "A Grande Família - 0

Filme" e "The Big Family - The Film": a tradução no ensino comunicativo de línguas

(MARILDA) -Ah, Carlinhos! Boa noite.

(LINEU) -Eu posso me esconder no quarto?

(NENÊ) - Não se atreva. A gente tem visita.

(CARLINHOS) -A última vez que a gente se viu foi num baile, 40 anos atrás.

(MARILDA) - Mas você sabe que a Nenê e o Lineu vão nesse baile até hoje?

-Eu acho isso tão romântico.

(NENÊ) - Eu tive uma ideia!

o Carlinhos e a Marilda, eles podiam ir ao baile com a gente.

(MARILDA) -Ótima ideia.

(TUCO) -Péssima ideia.

(BEBEL) -Família, vocês não sabem da novidade. O Tinho não é mais oco!

(AUGUSTINHO) -Não fala assim, tem uma visita.

(NENÊ) -Carlinhos, essa é a Bebel, nossa filha, e o Augustinho, nosso genro.

(TUCO) -Esse aí é o Carlinhos, o exnamorado da mamãe.

(NENÊ) -Tuco, ele não é meu ex-namorado.

(TUCO) -Carlinhos, ex-alguma coisa da mamãe.

(NENÊ) - Tuco, quer deixar a Bebel contar a novidade? -Fala, minha filha.

(BEBEL) -Então... o Tinho tá fazendo um tratamento, né? Aí hoje ele fez um exame lá no... Lá.

(MARILDA) -Lá onde?

(AUGUSTINHO) -Lá, Marilda. Onde o sol não
(MARILDA) -Carlinhos! Good evening.

(LINEU) -May I make myself scarce?

(NENÊ) -Don't you dare. We've got a guest.

(CARLINHOS) -Last time we saw each other was at a ball, 40 years ago.

(MARILDA) -Did you know that Nenê and Lineu still go to that ball every year?

-I think that's so romantic.

(NENÊ) -I have an idea!

Carlinhos and Marilda could go to the ball with us.

(MARILDA) -Great idea.

(TUCO) -Terrible idea.

(BEBEL) -Folks, you'll never guess what's new. Tinho ain't hollow anymore!

(AUGUSTINHO) -Don't say that, we've got a guest.

(NENÊ) -Carlinhos, this is Bebel, our daughter, and our son-in-law.

(TUCO) -This is Carlinhos, Mom's ex-boyfriend.

(NENÊ) -Tuco, he's not my ex-boyfriend.

(TUCO)-Carlinhos, Mom's ex-something.

(NENÊ) -Tuco, let me hear what your sister has to say. You were saying, Bebel?

(BEBEL) -Well, Tinho's been doin' this treatment, right? So, today, he went for an examination... down there.

(MARILDA) -Down there where?

(AUGUSTINHO) -Where the sun don't shine, 
Esqueda, M. D.; Oliveira, R. C. e J esus, S.M.- "A Grande Família - 0

Filme" e "The Big Family - The Film": a tradução no ensino comunicativo de línguas

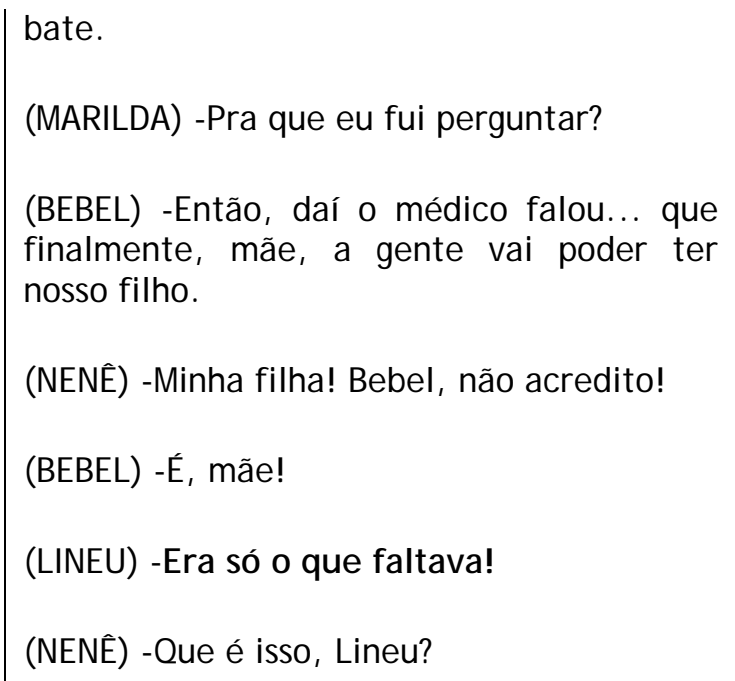

Marilda.

(MARILDA) -Why did I have to ask?

(BEBEL) -And the doctor said... that we'll finally be able to have a kid of our own, Mom.

(NENÊ) -Darling! Bebel, I cannot believe it!

(BEBEL) - Yeah, Mom!

(LINEU) -That just takes the cake!

(NENÊ) -What, Lineu?

(LINEU) -Nenê, I won't be around forever to foot Bebel and Augustinho's bills! That child needs a responsible father, with a steady job...

.... legally registered one!

(AUGUSTINHO) -What are you talking about?

-I got my cab.

(LINEU) -Parked around the corner all day!

(AUGUSTINHO) -Waitin' for a ride.

(LINEU) -Waiting for the cab driver...

while he drinks and shoots his rent money away on a pool table!

(BEBEL) -Dad!

\section{(LINEU) - God works in mysterious ways.}

If Augustinho couldn't have children, it'd be better to leave it at that!

(NENÊ) - Have you gone insane, Lineu?!

(LINEU) -I've got my reasons, Nenê.

(TUCO) -Such a nice atmosphere, huh?

(CARLINHOS) -Well, if it'd help... 
Esqueda, M.D.; Oliveira, R. C. e J esus, S.M.- "A Grande Família - 0

Filme" e "The Big Family - The Film": a tradução no ensino comunicativo de línguas

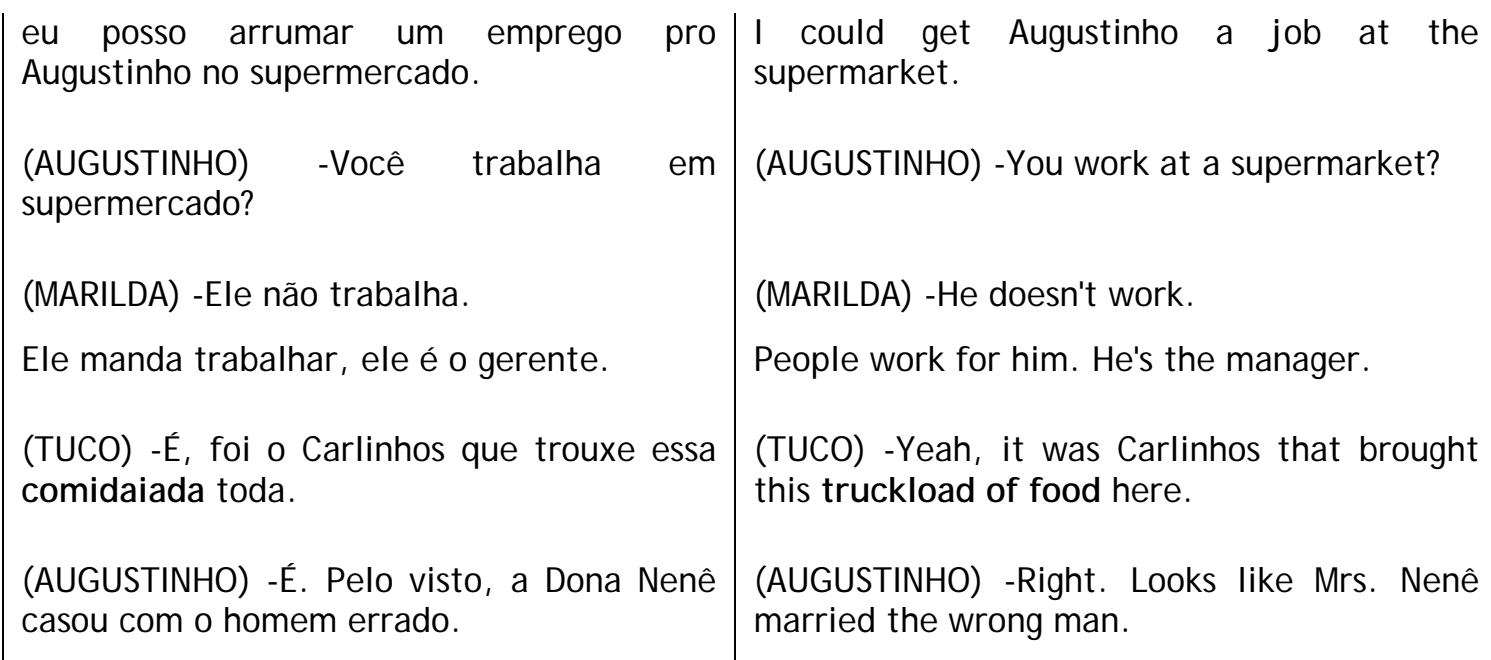

